\title{
Considerações sobre a Ampliação da Intensão da Psicanálise numa Unidade de Pronto Atendimento
}

\author{
Maico Fernando Costa ${ }^{1}$ \\ Abílio da Costa-Rosa ${ }^{1}$

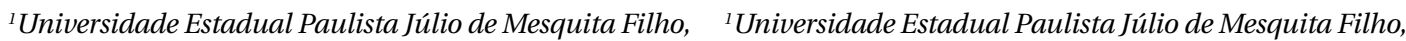 \\ SP, Brasil. \\ SP, Brasil.
}

\begin{abstract}
Resumo: Este artigo tem o intuito de tratar da práxis de um psicólogo precavido pela Psicanálise de Freud e Lacan na Urgência e Emergência de uma Unidade de Pronto Atendimento (UPA), na tentativa de operar com o dispositivo Clínica da Urgência. O dispositivo Clínica da Urgência, em nossa proposição teórico-clínica e ético-política, almeja a escuta dos sujeitos em sofrimento. Discorremos sobre seu posicionamento nesse campo de ação em especial e como se deram as tentativas de ampliar a escuta, a um lugar outro, diversamente do tradicional setting analítico. Para este exercício teórico, a Psicanálise foi o principal instrumento de trabalho, e recorremos a textos de psicanalistas autores que utilizam a Psicanálise freud-lacaniana para (re)pensar sua práxis analítica. Portanto intencionamos compartilhar a experiência da ação-reflexão do psicólogo nesse campo específico da Atenção em Saúde. Por meio da exposição de fragmentos de casos, de alguns atendimentos de sujeitos, a perspectiva foi pensar sobre estes no âmbito da intensão ampliada da Psicanálise. Concluímos que, nesse modo de compreensão da Clínica da Urgência, encontra-se um piso sólido aos horizontes da Psicanálise, essencial à escuta do sujeito do inconsciente em seus impasses e em seus processos de adoecer.
\end{abstract}

Palavras-chave: Psicanálise de Freud e Lacan, Unidade de Pronto Atendimento, Intensão Ampliada da Psicanálise, Sujeitos em Sofrimento.

\section{Considerations about the Enlargement of the Intention of Psychoanalysis in the EUC}

\begin{abstract}
This article intends to talk about the praxis of the psychologist, practitioner by the Freud-Lacan's psychoanalysis in the Urgency of an Emergency Unit Care (EUC), in an attempt to operate with the Clinic of Urgency device. The Clinical of the Urgency device in our theoreticalclinical and ethical-political proposition aims to hear the suffering subjects. We discuss his position in this field of action in particular and how the attempts enlarge de hearing to extend that to a different place, from the traditional analytical setting. This is a theoretical exercise, an instrument of psychoanalytic work, a resource of psychoanalytic texts, authors, who use Freud-lacanian psychoanalysis to (re) think their analytical praxis. Therefore, we intend to share the psychologist's action-reflection experience in this specific field of Health Attention. By exposing fragments of some cases, to think on these within the scope of the expanded psychoanalysis. We conclude that in this way of understanding the Urgency, a solid floor is found in the horizons of Psychoanalysis, essential for listening to the subject of the unconscious in its impasses and in its processes of falling ill.
\end{abstract}

Keywords: Freud and Lacan Psychoanalysis, Emergency Care Unit, Expanded Psychoanalysis, Suffering Subjects. 


\title{
Consideraciones sobre una Ampliación de Intenso da Psicanálise una UPA
}

\begin{abstract}
Resumen: Este artículo tiene el intuito de tratar la práxis del psicológico precavido por la psiconálisis de Freud y Lacan en la Urgencia y Emergencia de una Unidad de Pronto Atendimiento (UPA), en la tentativa de operar con el dispositivo de la Clínica da Urgencia. El dispositivo Clínica de La urgencia en nuestra propuesta teórico-clínica y ético-política almeja la escuta dos sujeitos en sofrimento. Discorremos sobre su posicionamiento neste campo de acción en especial y cómo se deram las tentativas de ampliar una escucha, a un lugar otro, diverso de la configuración tradicional do setting analítico. Para este ejercicio teórico, el psicoanálisis fue el principal instrumento de trabajo, recurrimos a textos de psicoanalistas, autores, que utilizan del psicoanálisis freud-lacaniana para (re) pensar en su praxis analítica. Por lo tanto, intencionamos compartilhar una experiencia de la acción-reflejo del psicólogo en este campo específico de Atención en Salud. Por meio de la exposición de fragmentos de casos, de algunos atendimientos de sujeitos, la perspectiva fue pensar sobre estos no ámbito de la intenso de la psicanálise aplicado al contexto hospitalario. Concluimos que en ese modo de comprensión de la Clínica de la Urgencia se encuentra un piso sólido a los horizontes del Psicoanálisis, esencial a la escucha del sujeto del inconsciente en sus impasses y en sus procesos de enfermar.
\end{abstract}

Palabras clave: Psicoanálisis de Freud y Lacan, Unidad de Atención de Emergência, Psicoanálisis Expandido, Sujetos en Sufrimiento.

\section{Introdução}

Este artigo é um fragmento originado de uma dissertação de mestrado que teve como propósito refletir sobre a práxis de um psicólogo precavido pela Psicanálise de Freud e Lacan, na tentativa de operar com o dispositivo "Clínica da Urgência” na Urgência e Emergência de uma Unidade de Pronto Atendimento (UPA) ${ }^{1}$ do Interior Paulista. O dispositivo Clínica da Urgência, na proposição teórico-clínica e ético-política adotada, almeja a escuta psicanalítica dos sujeitos em sofrimento que chegam e/ou estão em tratamento num equipamento de Saúde hospitalar (Moura, 2000). A hipótese é que, ao experimentarem a oportunidade de falar da dor e do acidente que os levaram à unidade hospitalar, eles criam algo de produção de sentido, ressignificando, dessa forma, sua relação com o sintoma e a "doença" diagnosticada pela equipe médica (Calazans \& Bastos, 2008;
Calazans \& Marçal, 2011). Para a operacionalização da Psicanálise na perspectiva da Clínica da Urgência, investimos na ideia de ampliar as possibilidades de ação da Psicanálise em "intensão", tal como foi concebida por Jacques Lacan (2001/2003a). O objetivo com este trabalho é discorrer sobre o que foi o posicionamento do psicólogo precavido pela Psicanálise nesse campo de ação em especial, uma UPA, e como se deram as tentativas de ampliar a escuta, a um lugar outro, diversamente do tradicional setting analítico.

Para este artigo, a Psicanálise foi o principal instrumento, método, de trabalho, recorremos a textos de psicanalistas, autores, que utilizam da psicanálise freud-lacaniana para (re)pensarem a sua práxis analítica. Intencionamos compartilhar a experiência da ação-reflexão do psicólogo estagiário nesse campo específico da atenção hospitalar².

\footnotetext{
${ }^{1}$ As UPAs estão em atividade 24 horas diárias, todos os dias da semana, inclusive aos sábados, domingos e feriados. Elas têm a função de ser a porta de entrada da urgência e emergência, comprometendo-se em oferecer a retaguarda aos hospitais gerais, para os casos mais graves que precisarem de uma estabilização inicial e posterior encaminhamento à alta complexidade da Rede de Saúde. Além disso, são incumbidas de realizar os procedimentos médicos primários, feitos costumeiramente nas Unidades Básicas de Saúde (UBS) e pela Estratégia Saúde da Família (ESF), quando estas não estão funcionando (Brasil, 2013).

${ }^{2}$ Com a autorização da Secretaria de Saúde Municipal, este foi o termo que escolhemos para nomear a função de um psicólogo que não era contratado ou concursado pelo estabelecimento de saúde. Para além das intenções com o curso de mestrado, o nosso desejo foi aprimorar a função de prática de escuta, enquanto experiência e formação em Psicanálise, em um dos estabelecimentos da atenção hospitalar, na UPA do município.
} 
Por meio da exposição de fragmentos de casos, de atendimentos de sujeitos, o intuito foi pensar sobre estes, no âmbito da "intensão ampliada" da Psicanálise. Durante a escrita deste artigo, escolhemos conjugar, não necessariamente nessa ordem, os pronomes pessoais na primeira pessoa do plural, primeira e terceira pessoas do singular. Os fragmentos da realidade estão sendo tratados no texto, onde existiu a minha participação como psicólogo, em primeira ou terceira pessoa do singular; na primeira pessoa do plural, são explicitadas as tentativas de elaboração teórica em conexão com seus diferentes intercessores.

A realização do exercício teórico que teve como base a vivência clínica na unidade hospitalar foi aprovada pelo Comitê de Ética em Pesquisa da Universidade Estadual Paulista "Júlio de Mesquita Filho" - Campus de Assis (SP), sob parecer no 2001219, atendendo às exigências éticas previstas na Resolução no 466/2012, do Conselho Nacional de Saúde, e na Resolução $n^{\circ}$ 10/2012, do Conselho Federal de Psicologia.

\section{A ampliação da “intensão": oferta, escuta e tratamento na UPA}

Visamos a definir a Psicanálise em intensão para, assim, tecermos algumas considerações sobre a proposta de ampliação deste conceito, transpondo-o para o âmbito da Saúde situada na atenção hospitalar. Dentro de esforços, na experiência do psicólogo (neste caso, como psicólogo precavido pela Psicanálise), ilustramos com os fragmentos da práxis as tentativas que houve de operar com o que nomeamos de "alargamento das possibilidades do campo da 'intensão comum' da psicanálise ${ }^{3 "}$.

Em seu texto Proposição de 9 de outubro de 1967 sobre o psicanalista da Escola, Lacan definiu a Psicanálise em extensão e a Psicanálise em intensão:

Para introduzi-los nisso, eu me apoiarei nos dois momentos da junção do que chamarei, neste arrazoado, respectivamente, de psicanálise em extensão, ou seja, tudo o que resume a função de nossa Escola como presentificadora da psicanálise no mundo, e psicanálise em intensão, ou seja, a didática, como não fazendo mais do que preparar operadores para ela (Lacan, 2001/2003a, p. 251).
Noutras palavras, lemos a Psicanálise em extensão como o locus de transmissão do saber psicanalítico estabelecido nas Escolas de formação, na estrutura dos Cartéis, nos espaços construídos para a formação do analista. Entendemos também como o a posteriori da escuta clínica, quando aquele que se instrumentaliza pela ética do sujeito está refletindo sobre sua prática. Em 1966, quando perguntado por um de seus alunos se era suficiente explicar a Psicanálise em um quadro, por meio do esquema de seu grafo, Lacan respondeu que, se um entre duzentos conseguisse lhe escutar, a Psicanálise teria seu futuro assegurado (Lacan, 1966/2001). Baseado na Psicanálise em extensão, extraímos quatro presunções: a) a experiência da psicanálise é singular; b) é preciso que fundamentalmente haja o desejo pelo saber por quem a quer experimentar; c) não devemos tomar seus ensinamentos por um imperativo universal na onda do "se é para um, tem que ser para todos"; e d) no que toca a sua sequência, seus avanços só serão conquistados na medida em que houver espaços para discuti-la, problematizando os efeitos de sua práxis.

Dito isso, a Psicanálise em intensão é a base pela qual a Psicanálise em extensão irá se amparar em seu funcionamento, é a Clínica propriamente dita. Lacan (2001/2003a) a anunciou como a didática, o local de preparação e formação de psicanalistas. Enxergando por este ângulo, é o sujeito numa análise e, posteriormente, este mesmo sujeito, caso seja do seu desejo, ocupando o lugar de analista. Esses movimentos não precisam ter um encadeamento linear, mas a análise pessoal e a prática analítica devem estar entrelaçadas. Segundo Lustosa (2003) e Soares (2009), tanto a extensão quanto a intensão são nucleares para o exercício da Psicanálise, exigem seus operadores teórico-técnicos na escuta ao sujeito do inconsciente (Rinaldi \& Alberti, 2009).

Partimos de Luciano Elia e, em especial, de Abílio da Costa-Rosa, para acrescentar o significante "ampliação" à Psicanálise em intensão. Tratando-se do trabalho do psicanalista na instituição de Saúde Mental, Elia (2010) falará em ampliação do dispositivo psicanalítico em intensão. A configuração espaço-tempo do dispositivo psicanalítico é modificada, porém sua estrutura é mantida; o "método" teórico-clínico e a ética que visa o sujeito na fala sob

${ }^{3}$ Essa noção de ampliação da Psicanálise em intensão advém de Costa-Rosa (2015). Ela está explorada em um texto ainda não publicado, intitulado "Por que a atenção psicossocial exige uma clínica fundada na Psicanálise do Campo Freud-Lacan?". 
transferência são os mesmos. A modificação introduzida na sua configuração de espaço e de tempo se refere à arquitetura do local, ao mobiliário, à ausência do divã, muitas vezes à falta de uma sala exclusiva para as escutas dos sujeitos. Não podemos deixar de mencionar ainda as interrupções dos atendimentos vindas de fora por parte da equipe, a inexistência de um horário estipulado para início e término de uma sessão ou entrevista e, em algumas situações, uma escuta que se faz no instante em que há trabalhadores por perto. Contudo a estrutura do dispositivo é mantida com a posição sustentada por um analista, agenciando o sujeito a ocupar o lugar do trabalho em seus processos de elaborar a angústia, bem como seus impasses.

Costa-Rosa (2015) prefere falar de alargamento das possibilidades do campo da "intensão comum" da Psicanálise. Nessa proposição, as novas configurações de espaço-tempo também são contempladas, bem como a manutenção do método psicanalítico e a ética do sujeito em seu bem-dizer. A novidade que se instaura, no que se difere de Elia (2010), é a ação do psicólogo, preocupado e atento à instituição. A perspectiva é ser harmônico com o que o próprio Freud (1919[1918]/1996) previra em "Linhas de progresso na terapia psicanalítica”, quando pensava numa psicanálise para os povos: o locus de exercício da Psicanálise não está limitado ao local físico, está onde há as possibilidades de acesso ao inconsciente, onde há um analista e um sujeito para falar de suas dores, das questões que interpelam o aparelho psíquico. Vejamos que, na propositura de Costa-Rosa (2015), o fundamental não será a Psicanálise na instituição, mas uma instituição em que a Psicanálise possa caber; para tanto, as ações do psicólogo precavido pela Psicanálise implicarão em operar com uma escuta que não seja à revelia do estabelecimento institucional.

Alargar as possibilidades da "intensão comum" é ter a atenção voltada a nuances que fazem a diferença na escuta empreendida pelo psicólogo. Herdada do institucionalismo francês e da Psicoterapia Institucional, este trabalho parte de uma concepção segundo a qual o estabelecimento institucional se transforma em intermediário necessário no tratamento dos sujeitos em sofrimento, concebe-se a importância na suposição de saber por parte dos trabalhadores naquele que escuta os sujeitos. Nesse ínterim, o manejo da transferência, de certo modo, também se estende à equipe, visando a uma prática entre vários, entendendo quão válido é um tratamento psíquico ofertado aos sujeitos do sofrimento sem estar dissociado e alheio à participação dos demais trabalhadores inseridos no estabelecimento. Segundo Figueiredo (1997), em relação à presença do psicanalista na instituição de saúde e para que sua prática tenha reconhecimento por parte das equipes, o intuito não é convencer, mas, sim, conviver com os trabalhadores, seus colegas de trabalho.

Deve-se encarar a ampliação da Psicanálise em intensão como a abertura a diálogos com referenciais homólogos de estatuto ético, objetivando superar as disciplinas e o princípio dualista sujeito-objeto (doença-cura) que as caracterizam. O materialismo histórico de base marxiana, por exemplo, seria, na nossa leitura, o que pode nos oferecer uma compreensão de instituição, indicando-a como um produto das formações sociais, logo um palco de lutas políticas (Costa-Rosa, 2013a; Lourau, 2014). Entendemos que uma produção de saúde enquanto produção de saúde psíquica, saudessubjetividade ${ }^{4}$, está atrelada a esses jogos de forças, a produção da vida material está intimamente atrelada à produção da vida social (Costa-Rosa, 1987, 2013b; Luz, 1979).

Destarte, a respeito da ampliação da Psicanálise em intensão, interessamo-nos pelo que disse CostaRosa (2015), que ela se expressa no fato de trabalharmos para adequar o dispositivo institucional de maneira que a Psicanálise possa caber nele, propiciando que a instituição se torne um espaço franco na escuta aos sujeitos que estão em tratamento. Nessa concepção do conceito estão inclusos o trabalho cooperado, o compartilhamento de saberes com a equipe e o intuito em instrumentalizar posições dos trabalhadores que possam ser intercessoras junto aos sujeitos em tratamento, em seus processos de lidar com o sofrimento e a "doença".

O manejo do Dispositivo Analítico, do tradicional setting analítico, a manobra por ampliá-lo, na UPA em que estivemos, acompanhava a urgência na rápida resposta clamada pelos sujeitos na sua angústia. Perante a realidade abalada, faltava um sentido ao trauma. Em sua demanda, reivindicavam, na pujança de sua dor, um saber para dar um nome ao acidente e aliviar (curar) o seu sofrimento. Diante do

${ }^{4}$ A produção de saúde é indissociável da produção de subjetividade (Costa-Rosa, 2013a). 
exposto, vale a pergunta: na UPA, o psicólogo precisaria então ser rápido no raciocínio? Garantimos que sim, contudo ressaltamos que os elementos da experiência de práxis e da própria análise do operador da escuta são a pedra de toque para a peculiaridade dessa escuta são.

Nos termos da técnica, da teoria e da política, a estrutura da Psicanálise conduzida na Clínica stricto sensu foi possível de ser assegurada na UPA. Geralmente, os sujeitos em tratamento permaneciam no estabelecimento por no máximo 24 horas, o que era suficiente para operarmos com a fala, por meio das entrevistas preliminares, da transferência, do corte e da escansão (Quinet, 2005). A postura do psicólogo na práxis delimitou-se em atuar para que os sujeitos viessem a trabalhar subjetivamente e falar de seus incômodos (que, na sua maior parte, eram físicos).

De entrada, mais do que alcançar um êxito terapêutico na escuta, as indicações freudianas foram seguidas-atuamos para proporcionar aos sujeitos uma tomada de consciência acerca das agruras que os acometiam. Notamos esse preceito nas palavras de Freud (1909/1996b), que diz que o "sucesso terapêutico, entretanto, não é o nosso objetivo primordial; nós nos empenhamos mais em capacitar o paciente [sujeito] a obter uma compreensão consciente dos seus desejos inconscientes" (p. 110). O reconhecimento, por mais inicial que seja, de que existem pontos em sua história relativos à experiência do seu psiquismo, no confronto com o traumático, já é um primeiro passo dado pelo sujeito. Portanto, para que cheguemos a este alvo, no entendimento de Lacan (1966/1998a), o que o psicanalista dirigirá nessa operação não será o sujeito, mas, sim, o tratamento. $\mathrm{O}$ analista empresta seu corpo e sua subjetividade como suporte aos fenômenos da transferência. Os fenômenos da transferência que, por sua vez, são eventos úteis para a precipitação da palavra, como forma de articulação do que está não-dito em direção ao [bem-]dizer.

Por volta do ano de 1893, aproximadamente, em um dos textos de Freud, dos chamados pré-psicanalíticos, encontramos a reflexão sobre um caso atendido por ele no alto de uma montanha. Ainda que seja um ensaio antigo e representante dos rudimentos da Psicanálise, acreditamos que ele ilustra um pouco o que é uma de nossas propostas. Valemo-nos do caso Katharina como exemplar das possibilidades de escuta que estão longe de uma sala com seu divã e suas poltronas.
Nas férias de verão do ano de 189[3] fiz uma excursão ao Hohe Tauern para que por algum tempo pudesse esquecer a medicina e, mais particularmente, as neuroses. Quase havia conseguido isso quando, um belo dia, desviei-me da estrada principal para subir uma montanha que ficava um pouco afastada e que era renomada por suas vistas e sua cabana de hospedagem bem administrada. Alcancei o cimo após uma subida estafante e, sentindo-me revigorado e descansado, sentei-me, mergulhando em profunda contemplação do encanto do panorama distante. Estava tão perdido em meus pensamentos que, a princípio, não relacionei como estas palavras, quando alcançaram meus ouvidos: "O senhor é médico?” Mas a pergunta fora endereçada a mim, e pela moça de expressão meio amuada, de talvez dezoito anos de idade, que me servira a refeição e à qual a proprietária se dirigira pelo nome de "Katharina". A julgar por seus trajes e seu porte, não podia ser uma empregada, mas era sem dúvida filha ou parenta da hospedeira.

Voltando a mim, respondi:

- Sim, sou médico, mas como você soube disso?

- O senhor escreveu seu nome no livro de visitantes. E pensei que, se o senhor pudesse dispor de alguns momentos... A verdade, senhor, é que meus nervos estão ruins. Fui ver um médico em L - por causa deles, e ele me receitou alguma coisa, mas ainda não estou boa.

...-Bem, e de que é que você sofre?

- Sinto muita falta de ar. Nem sempre. Mas às vezes ela me apanha de tal forma que acho que vou ficar sufocada (Freud, 1893/1996c, p. 151).

Diante da demanda de Katharina, Freud (1893/1996c) se perguntou: "Deveria eu fazer uma tentativa de análise? Não podia aventurar-me a transplantar a hipnose para essas altitudes, mas talvez tivesse sucesso com uma simples conversa" (pp. 152-153). Freud poderia achar que esse encontro seria uma simples conversa, porém o conteúdo dos impasses trazidos por Katharina, envolvendo seu tio, a sexualidade e os sintomas corporais, revelava um sujeito que muito poderia se favorecer de uma experiência analítica. Talvez não fosse a pretensão de Freud atuar com a psicanálise naquele contexto. A despeito disso ou não, da enxurrada de perguntas direcionadas à Katharina 
serem invasivas demais ou não, observamos nas linhas do texto que ela se beneficiara dos efeitos de sua fala, conseguindo se dar conta de coisas que permaneciam inconscientes, até então veladas pela barra do recalque, não lhe sendo acessíveis pela consciência até aquele dia. Notemos que as condições criadas por Freud para que o sujeito, Katharina, pudesse encontrar na sua própria fala a verdade recalcada do seu sintoma não se opunham radicalmente ao manejo do tratamento analítico em seu consultório. Não obstante, erguer preceitos para a práxis psicanalítica no contexto institucional se faz mister.

Alguns parâmetros técnicos foram levados em conta para nossa prática clínica na UPA. Incorporamos os três momentos da urgência subjetiva, relacionados ao dispositivo Clínica da Urgência e propostos por Calazans e Bastos (2008): a relevância em se considerar o modo como o sujeito se precipitou na instituição e a existência ou não de uma transferência selvagem (sem análise) na relação com o analista; a recepção do sujeito e a instalação da transferência (em vias de ser analítica), a suposição de saber no psicólogo; e o momento de pensar os encaminhamentos para a continuidade do tratamento psíquico noutro estabelecimento da rede. Outrossim, associamos a esses três momentos as seis proposições de Jacques Lacan (1966/1998a) em A direção do tratamento e os princípios de seu poder.

Para onde vai, portanto, a direção do tratamento? Talvez baste interrogar seus meios para defini-la em sua retidão.

Observe-se:

1) Que a fala tem aqui todos os poderes, os poderes especiais do tratamento;

2) Que estamos muito longe, pela regra, de dirigir o sujeito para a fala plena ou para o discurso coerente, mas que o deixamos livre para se experimentar nisso;

3) Que essa liberdade é o que ele tem mais dificuldade de tolerar;

4) Que a demanda é propriamente aquilo que se coloca entre parêntese na análise, estando excluída a hipótese de que o analista satisfaz a qualquer uma;

5) Que, não sendo colocado nenhum obstáculo à declaração do desejo, é para lá que o sujeito é dirigido e até canalizado;
6) Que a resistência a essa declaração, em última instância, não pode ater-se aqui a nada além da incompatibilidade do desejo com a fala (p. 647).

Assentamos a práxis sobre as linhas de condução que a escuta analítica preceitua. Baseamo-nos nessa direção do tratamento, na fala em seu curso livre, na não resposta à satisfação da demanda e na dissipação de gozo angustioso que pode haver no encontro da palavra com o desejo (inconsciente).

Parte da equipe comentava: "pena que você não tem uma sala", e a resposta dada sempre era que a escuta poderia se operar onde houvesse pessoas para falar, a sala poderia estar em todos os lugares. Ouvia de outro trabalhador, munícipe de uma cidade próxima, que na Santa Casa de Misericórdia do seu município havia um psicólogo, porém ele não ficava circulando, ficava somente na sua sala esperando os encaminhamentos. Ao contrário disso, optamos perambular por todos os lados, sem ter um local próprio para os atendimentos, pelos corredores, na recepção (Sala de Espera), pelas Salas de Observação, Inalação, Hidratação, nas proximidades da Sala de Urgência e Emergência.

Os acontecimentos exigiam jogo de cintura e improvisação da parte do psicólogo. Nas Salas de Observação, os leitos ficavam próximos uns dos outros, havia os sujeitos e seus acompanhantes. Por vezes, estava próximo de um sujeito em seu leito e, ao lado, havia outro tentando ouvir o que dizíamos. Quando era possível, fazia o convite ao sujeito que escutava para nos locomovermos a um espaço mais reservado. Buscava não me expor e não expor muito quem falava, falar em um tom de voz baixo. Durante o expediente, procurava entrar uma ou duas vezes no máximo em cada Sala de Observação. O desafio foi introduzir a dimensão de escutar o sujeito do inconsciente numa UPA. E como fazer acontecer esse tipo de tratamento num lugar onde antes isso não se propunha?

Então, onde há oferta pode surgir a demanda, e se surge a demanda é porque existe, em algum lugar, a possibilidade de ser escutada. Se alguém não se sente bem em oferecer a sua escuta, é preciso trabalhar isso em sua própria análise, se deseja ser analista, pois o que pode fazer um analista é, antes de tudo, oferecer-se. Oferecer apenas, para ser mais clara, a sua escuta (Moretto, 2001, p. 109). 
Todavia aproximava-me dos sujeitos que emitiam algum sinal, seja pelo semblante esmorecido, deprimido, triste ou por seu olhar "perdido". E não poderiam ser estes os sinais parte daquele sinal que não engana, tão conhecido no sofrimento psíquico, a angústia?

Em um contexto em que a palavra é surrupiada para dar lugar à dor, o menor aviso, a menor comunicação por parte dos sujeitos é motivo para se prestar atenção. Buscando gerar a demanda por intermédio da oferta, um uso de táticas para chegar aos leitos foi feito, às vezes olhava pelo vidro, do lado de fora das salas. Permanecia próximo dos técnicos de Enfermagem, responsáveis pelas Salas de Observação, para estabelecer um fio de conversa a respeito do trabalho ou de qualquer outro assunto. Nessa oportunidade, averiguava com os técnicos sobre as demandas de escuta no local ou dirigia-me àqueles sujeitos que estavam sozinhos ou acompanhados, solicitando ao acompanhante que nos deixasse a sós por um instante.

Noutras situações, transitava pelo corredor e pela recepção para que as pessoas enxergassem meu crachá e viessem a mim. Interessante como muitos, depois dos atendimentos, supunham qual era o meu papel na UPA pela posição "atenciosa" que aparentava a eles. Diferenciavam-me do restante dos trabalhadores por esse aspecto. Certa vez, disse-me um sujeito: "você tem mesmo o jeito de psicólogo. Você escuta".

Os sujeitos que pude escutar enquanto psicólogo, em suas falas, não sabiam de onde vinha a dor, e em diversas circunstâncias a equipe médica também não sabia. Foram casos de hipertensão, dores de cabeça, perdas da voz, indício de enfarto, conversões histéricas, acidentes diversos; por alguma razão esses sujeitos estavam na UPA.

Os trabalhadores reconheciam que era trabalho para o psicólogo somente quando os sujeitos estavam chorando, quando estavam dizendo algo que os levava a entender que era um "problema" emocional. As dores de cabeça, dores pelo corpo, os desmaios, mesmo que não houvesse uma constatação médica que indicasse essas indisposições como de origem orgânica, ainda assim não eram motivo para que os trabalhadores inferissem que se tratava de uma questão de ordem psíquica. No máximo, arguiam que se tratava de um "piti": o sujeito estava fingindo.

Excetuando alguns casos, a maioria dos sujeitos que escutei foi a partir da minha oferta, por meio de perguntas, não todas ao mesmo tempo, porém utilizadas cada qual numa ocasião em que eu julgava pertinente: "Olá, como vai?", "O que aconteceu?", “Como está?". Se não vinham procurar o psicólogo, eu me apresentava.

\section{A Psicanálise noutro contexto}

Estamos apresentando a peculiaridade de um trabalho de Psicanálise em um lugar em que as questões relativas ao psiquismo não são o objeto principal de atenção por parte daqueles que acompanham os sujeitos em seus sofrimentos. No contexto hospitalar, os sintomas são notados pelas equipes em sua dimensão física, orgânica. Entretanto, em 1920, Freud (1920/1996) sinalizou um aspecto interessante da vivência do trauma. Ele nomeou de "neurose traumática" a condição vivida pelos sujeitos ao sofrerem acidentes, a eclosão de uma indisposição subjetiva e de uma perturbação do seu psiquismo em decorrência de eventos traumáticos. A distribuição da libido poderia ser debilitada em decorrência do dano físico. Observa-se que, seis anos antes, em 1914, Freud (1914/1996) já abordara o assunto:

uma pessoa atormentada por dor e mal-estar orgânico deixa de se interessar pelas coisas do mundo externo, na medida em que não dizem respeito a seu sofrimento. Uma observação mais detida nos ensina que ela também retira o interesse libidinal de seus objetos amorosos: enquanto sofre, deixa de amar (p. 89).

O instante em que o sujeito se encontra acometido pela dor infligida, sentida em seu corpo, é marcado por um abalo na realidade, a perda de contato com os objetos de desejo: o interesse no trabalho, as relações amorosas, os sonhos, as esperanças, as aspirações. A libido ligada ao objeto é vinculação aos objetos que despertam para a vida. Contudo, com o mal-estar orgânico, ocorre que a libido é desligada dos objetos externos e é voltada para o próprio $\mathrm{Eu}$, transformando-se numa pulsão de face destrutiva e mortífera - mortífera, neste caso, nos remete, sobretudo, a uma morte às impulsões de viver, aos anseios, às ambições de vida.

Posto isto, na ausência das palavras e de alvos para onde se investir libidinalmente, a escuta psicanalítica não deixa de supor um sujeito quem está padecendo diante dos eventos nos quais o mal-estar 
e a dor de existir parecem prevalecer. Serve-nos de modelo o exemplo dado por Lacan no seu Seminário livro 1: Os escritos técnicos de Freud, em que demonstra que o mestre budista, segundo a técnica zen, interrompe o silêncio com um pontapé, um sarcasmo, com qualquer coisa, tudo pela procura de um sentido (Lacan, 1975/1983). Visamos o sujeito interrompendo seu silêncio para que, por intermédio da fala, ele revitalize a ligação com os seus objetos de investimento libidinal que fazem a ele semblante de desejo e, desse modo, possa criar outros sentidos ao seu sofrimento.

Lembramo-nos do senhor $\mathrm{C}^{5}$. Ele estava sozinho em um quarto isolado, internado por artrose nas pernas e por um problema na bexiga. Perguntei como estava, e ele me respondeu sussurrando com ares de quem está sentindo muita dor: "não há dor maior no mundo". Após um tempo em silêncio, passaram-se alguns minutos e ele não continuou mencionando as dores no corpo. Então sublinhei: "não há dor maior?". Respondeu-me imediatamente: "não há dor maior do que a dor da saudade". A partir desse momento, o senhor C. falou do seu passado, de quando podia trabalhar, andar, do amor que tinha pelas filhas, das mulheres que gostou e da atual esposa. Era um senhor que aparentava 80 anos ou mais. Intuímos em criar condições para que o sujeito acessasse a polissemia de sentidos subjacentes ao mal-estar orgânico. À medida que se desloca do lugar de objeto de uma "doença", ou de um sintoma físico que o impede de viver, o adoecimento dos órgãos deixa de ser a única das preocupações em cena - há a chance de o sujeito se reconhecer como sujeito de uma história, e não somente como número de um prontuário.

Eleitos por nós, pretendemos expor os fragmentos das entrevistas preliminares de dois sujeitos que pudemos escutar, sob os esforços de exercitar o dispositivo Clínica da Urgência na UPA. Do nosso ponto de vista, estes são os casos que mais representam a clínica psicanalítica ampliada em sua "intensão".

As entrevistas preliminares em Lacan são o equivalente ao tratamento de ensaio para Freud; é um trabalho prévio para toda entrada em análise (Quinet, 2005). Neste propósito, o exercício das funções das entrevistas preliminares foi conduzido para a continuação dos seus trabalhos subjetivos nas UBS do seu território.

\section{Caso S.}

S. foi o primeiro sujeito que recepcionei por encaminhamento de um trabalhador da equipe. Ela estava na maca, com partes do corpo enfaixadas e com curativos cobrindo uma de suas faces, parecia ter se machucado muito. Tentou suicídio, não fiquei sabendo o que havia acontecido para que ela estivesse tão machucada e enfaixada, soube apenas que tomou muitas medicações para se matar. Estava por perto quando uma técnica de enfermagem e uma enfermeira disseram a ela que um psicólogo iria atendê-la. Subitamente, S. respondeu: "ah não, não quero chorar". Ao chegar próximo, a primeira coisa que me disse, olhando para mim e para a enfermeira, foi: “nossa, que moço bonito!'. Perguntou pelo meu nome e, ao me ouvir lhe responder, contou que era o mesmo nome do seu filho. Sua mãe me disse que S. não era muito de conversa. No entanto percebemos, ao longo do seu discurso, totalmente o contrário dessa afirmação.

S. falava do grande amor pelos filhos, sobretudo pelo filho que estava preso, "eles valem ouro pra mim". Sublinhei o significante "ouro", e ela continuou enfatizando que seu amor era grande. Não queria para eles a vida que teve. Citou a filha, afirmando que brigou com um rapaz que tentou assediá-la, disse que foi violentada na adolescência e não iria querer o mesmo para ela. $\mathrm{O}$ moço que gracejava a filha com cantadas insinuantes era um traficante que, além de tudo, segundo ela, era casado.

Revelou que sua mãe a ajudava cuidar dos filhos. S. contou que tinha depressão, não conseguia sair de casa, lembrou que uma psicóloga sempre lhe visitava, chamava-a, mas ela não queria sair para receber a psicóloga. Falava da tristeza que guardava consigo, pensava nos filhos dia e noite. Pontuei: “dia e noite?”. S. frisou que, se preciso fosse, daria a vida pelos filhos. Mencionou um filho que estava preso, na penitenciária da cidade, ele fazia uso de remédio controlado, psiquiátrico, disse ela.

A mãe de S. continuava por perto, complementava o que a filha dizia, revelou que, na ausência do seu neto, S. tomava os remédios por ele. Resolvi solicitar à mãe de S. conversar reservadamente com a filha. Na ausência da mãe, S. parecia falar de sua vida de maneira mais livre, contou que "guardava" segredos, estavam "guardados

\footnotetext{
${ }^{5}$ Tendo em vista os motivos éticos e por garantia de sigilo, para se referir aos sujeitos que tiveram suas falas apresentadas neste artigo, foram utilizadas iniciais fictícias de seus respectivos nomes, de modo a preservar as suas identidades originais.
} 
no peito". Silenciou-se e voltou a falar da sua tristeza, do quanto amava os filhos e se doía por eles. Pontuei: "é necessário falar do que está guardado".

S. começou a dizer sobre como foi violentada por três homens e do medo do evento se repetir com a filha (que, a essa altura, tinha a mesma idade de $\mathrm{S}$. à época em que foi violentada). Disse $S$, chorando muito: "minha filha é uma mocinha muito bonita". Exprimiu não saber o porquê de ter tanto medo pelos filhos e de não conseguir sair de casa. Perguntei: "é o que se sabe e se tem?”. Respondeu S.: “eu sei que eu tenho coisas aqui dentro comigo que só eu posso resolver. Me dói muito isso". Fui encerrando a entrevista, disse a ela que havia coisas em aberto que mereciam ser trabalhadas numa psicoterapia. S. assentiu com a cabeça, falou que iria esperar a psicóloga lhe atender em casa. Pontuei firmemente: "é importante que você procure", ela limpou as lágrimas, agradeceu-me e disse que iria procurar.

Certo dia, uma enfermeira contou-me que, sempre quando estava na UPA, S. sentava-se na Sala de Espera e dizia à enfermeira que vinha me ver. Fiquei em silêncio e, em seguida, falei: "talvez ela vir para me ver tenha a sua função, quando vê-la, por favor, avise-me que vou até ela". A técnica de enfermagem concordou, complementando que era importante uma escuta para as pessoas que sofriam acidentes e estavam internadas por uma doença.

\section{Caso CM.}

Pude escutá-lo em três oportunidades num mesmo dia: no primeiro momento, apenas perguntei como estava, respondeu estar tranquilo, aguardava exames para saber de uma dor no peito que os médicos não souberam lhe responder. Ficou quieto, não disse mais nada. Afastei-me propositalmente, falei que era o psicólogo e que estaria circulando pela Unidade. Na segunda vez, ao encontrar com CM. no corredor, para iniciar a oferta de uma escuta, estrategicamente começo um diálogo. Perguntei sobre os exames, respondeu-me que ainda não sabia de nada, "é uma dor no peito só, não é nada demais". Disse-lhe: "às vezes uma dor fala de outras dores", CM. sorriu e falou, "eu estou bem, meu problema não é de amor, não. Tenho saudade dos meus pais, mas já os vi recentemente”. Sublinhei: “amor?”. CM. responde:

É, fui casado duas vezes, no segundo casamento, a mulher largou de mim. Quis morrer, me joguei no asfalto, tive um apagão, aí acordei e estava no acostamento. Quase um caminhão me pegou, mas alguém me salvou. Estou sozinho hoje, mas está bom assim. Estou bem.

Digo para ele que continuaríamos aquela conversa noutro momento, que depois gostaria de escutá-lo melhor. Ao dizer isso para CM., coincidiu com o técnico de enfermagem chamando-o para aplicar uma medicação intravenosa.

Depois de uns trinta minutos, avistei-o no corredor e o chamei para nos sentarmos em um banco, ao lado da Sala de Medicação. Por sorte, próximo ao banco não havia muitas pessoas circulando. Disse a ele que não tínhamos uma sala, porém aquele local não deixava de ser um lugar, "serão perguntas para saber como você está, é importante que diga o que lhe vier à mente". Fiquei em silêncio, ele olhou para mim e disse: "então tá, me pergunte?". Solicitei a CM.: "você falou sobre 'amor' da última vez. Continue". $\mathrm{CM}$. falou de como foi quando se separou da última esposa. Contou o quanto foi difícil, quis morrer, falou do quanto era ruim estar sozinho, morar sozinho, viajar como viaja. CM. trabalhava para uma empresa do Rio Grande do Sul, que o obrigava a viajar e ficar meses fora da sua terra natal. Disse que, recentemente, estava entrando em depressão por estar longe de casa. A empresa o havia liberado para voltar à casa dos pais por alguns dias. Continuou falando: "sou muito nervoso, fico inquieto. Fiquei na casa dos meus pais por uns dias, mas fico desinquieto". Perguntei: “des-inquieto?”. Respondeu:

Não aguento ficar parado. Você já viu, eu fico andando de um lado para o outro. Tomo até um "calmantizinho" paradormir, Rivotril,vocêconhece? Só assim pra dormir. Sou muito nervoso, desinquieto. Rapaz, como é dificil ficar sozinho, é muito triste não ter ninguém. A gente fica aí viajando de um lado para o outro. Mas é assim mesmo, já me disseram, não tenho cura, isso não tem cura.

Perguntei: “quem disse?". CM.: “ah, não tem cura mesmo, o que eu vou fazer? O que eu vou fazer, não tem solução mesmo". Encerrei: "sim. É o que você vai fazer". Frisei a ele que uma psicoterapia poderia ser um dispositivo interessante para as inquietações. CM., fitando-me com os olhos bem arregalados, me disse, "sabe que há um tempo atrás eu estava pensando nisso mesmo: pensando em procurar um psicólogo". 
Inicialmente, CM. não queria falar, dizia não ter nada, que não tinha nada para falar com o psicólogo. Notemos que as escansões realizadas proporcionaram ao rapaz querer falar de si e se haver com as coisas que lhe deixavam "desinquieto", impeliram o deslocamento do significante "dor no peito", fixado na queixa, para outro significante: "não sei por que sou assim, tão desinquieto e nervoso".

Vejamos os fragmentos da experiência. O caso S. é exemplar das manobras feitas na peculiar ação exigida ao psicólogo junto aos sujeitos no estabelecimento hospitalar. Sobre S., conseguimos extrair lacunas, falhas, consequências exitosas do agenciamento do seu caso? Nossa primeira resposta incide na equipe. S. veio até nós, ou melhor, tivemos conhecimento dela por meio do assistente social e do enfermeiro, devido à relação transferencial (no sentido psicanalítico) tecida com os trabalhadores. Se assim não tivesse ocorrido, dificilmente teríamos tomado conhecimento dela. Houve uma confiança depositada em um tratamento que fosse pela fala. Retomando o que a técnica de Enfermagem disse, das vindas de S. à Unidade para ver o psicólogo, depois de ser escutada por ele, considerando que não a viu mais, valeria ter ligado para saber como estava? Convidando-a para mais uma entrevista, para interrogarmos mais suas queixas? Em seu discurso, ela mencionou uma psicóloga. Teria ajudado se buscássemos informações sobre essa psicóloga, a contatássemos de modo que um projeto terapêutico fosse pensado entre a UPA e a UBS, visando uma atenção aos impasses psíquicos de S.?

Cabe uma constatação aqui. No início da práxis, eu escutava os sujeitos e, ao término das entrevistas, pedia para que retornassem no outro dia. Eram agendados uma data e horário com eles. Procedimento pelo qual me apoiei nas unidades de saúde anteriores em que trabalhei. Nesses locais, os sujeitos sempre voltavam. Na UPA, encontrei um cenário diferente; raríssimos foram os que retornaram. Perante a impossibilidade que se mostrava real, a saída foi procurar desvios, contornar os impedimentos para o seguimento das escutas. A estratégia foi marcar sessões sequenciais, com o intervalo de alguns minutos de uma para a outra, todas no mesmo dia. Foi preciso criar condições para manejar uma transferência anônima (sem análise) antes sustentada no discurso médico e na UPA, para uma transferência balizada no dispositivo analítico (Miller, 1989).
Tratemos de discutir as particularidades de CM. Em seu caso, havia uma dor no peito, da qual os médicos nada sabiam; ele estava à espera de exames. Segundo Miller (1989), nesse primeiro momento de encontro do sujeito com o dispositivo da Psicanálise, a transferência é anônima, vigoram as miragens imaginárias, acredita-se em um saber absoluto, na existência de uma resposta pronta ao sintoma que divide o sujeito. Essa transferência é semelhante às relações duais manifestadas entre um doente e um "médico, do paciente com o psicoterapeuta, do estudante com o professor" (Miller, 1989, p. 45). Foi como se CM. não estivesse apresentando seus sintomas ao psicólogo.

Entendemos que as pontuações das falas, os cortes das primeiras para as segundas e das segundas para as terceiras entrevistas provocaram mudanças no estatuto da transferência desses sujeitos em relação ao operador da psicanálise, psicólogo. Pontuamos os discursos, assinalando os significantes emergentes da fala, para abrir os sentidos e proporcionar que o saber absoluto fosse demolido em saber inconsciente, saberes múltiplos acerca da "doença". O corte, marcando o fim de uma sessão, tem esse objetivo.

Portanto, a função do corte, da pontuação, na análise, tem valor de interpretação no que comemora a repetição, no que reconhece, em ato, o sintoma do Outro recortando-o do enunciado em questão e isolando a significação à qual o sujeito está submetido (Nazar, 1985, p. 106).

O valor de interpretação que possui o corte, nessa medida, é pura escansão. A fala, ou trecho pronunciado, é decomposta como meio de dar destaque às palavras antes não percebidas. Os significantes dos ditos são sublinhados, privilegiando que os sujeitos os interroguem, desejando interpretá-los, e dizer diferentemente sobre a dor que lhes dilacera.

As segundas e terceiras entrevistas de CM. mostram-no falando de coisas outras, que não somente o sintoma-queixa, a "dor no peito". CM. falou dos antigos casamentos, da saudade dos pais e da esposa que o deixou. Revelou que, depois de se separar da ex-mulher, perdeu a vontade de viver; disse que não sabia por que era tão "desinquieto".

Ao fim das respectivas sessões, do que foi seu trabalho com o psicólogo precavido pela psicanálise, $\mathrm{CM}$. pareceu caminhar um pouco além de sua queixa inicial. Precisamente, ficaria difícil arriscarmos e afirmarmos 
que ele pôde fundar um laço transferencial com o tratamento a ponto de se posicionar em associação-livre, do mesmo modo como estaria se estivesse em uma análise propriamente dita. Esse sujeito não havia feito a passagem completa de uma transferência anônima para uma transferência em vias de se tornar analítica $^{6}$, mas, porventura, ele ainda estaria longe disso? Não desprezamos seu interesse em prosseguir com um tratamento psíquico, ele enunciou a intenção, confrontando-se com sua história, constituiu algo de enigma ao seu sintoma. Em seu caso - e por que também não nos demais que viveram uma experiência analítica na UPA? -, ter ficado mais "inquieto" e perguntando-se sobre seus próprios sintomas foi um passo fundamental no seu trabalho subjetivo, no que demonstramos dos efeitos de nossa práxis.

Muitos simplesmente não queriam falar, nem se queixavam de suas dores. Uns ancoravam-se na religião ou no discurso médico, única e irrestritamente, bastava-lhes isso. Havia os sujeitos do tratamento e acompanhantes que se interessavam em dizer de seus impasses a um psicólogo. Costumava me apresentar como tal, comunicava-lhes que estaria andando pela UPA e, caso resolvessem falar, poderiam procurar por mim na equipe. Por outro lado, constatamos que a maior parte se dispunha a ser escutada pelo psicólogo. Estavam na extrema angústia, por questões que desconheciam ou por problemas inicialmente fisiológicos. Curioso como ao se pronunciarem em primeira pessoa, a respeito de suas histórias, alguns declaravam que os sintomas físicos tinham se suprimido: as tosses, a falta de ar, ou as dores no peito, para exemplificarmos alguns dos sintomas físicos mais característicos.

Ficamos sabendo pouco dos desdobramentos dos casos atendidos, se houve continuidade ou não dessas escutas; mas podemos dizer que muitos foram os sujeitos que conseguiram se abrir para dimensões outras de sua queixa. Durante a atuação no estabelecimento, me reuni com os psicólogos da Atenção Básica localizados nas UBS do município. A perspectiva foi construir uma parceria com eles, uma compreensão mínima dos casos em rede e uma direção do tratamento que não se encerrasse na UPA. Após cada escuta com os sujeitos, indicava-lhes o nome e horário de atendimento do psicólogo, situado na UBS de seu território, nas proximidades de sua residência e bairro.

Perguntamos para que serviria o psicólogo na UPA e o que ele deveria saber para lá estar. Seguimos o famoso axioma de Lacan, conhecido igualmente por ignorância douta: "O que o psicanalista deve saber: ignorar o que ele sabe" (Lacan, 1966/1998b, p. 351). O psicólogo precavido pela psicanálise de Freud e Lacan está convocado a se amparar nessa sentença. Apostamos que não será ele a saber pelo outro, ou seja, curá-lo. Pelo contrário, atuará no máximo para que os sujeitos trabalhem seus impasses e para que os demais trabalhadores, intercessores do campo, interroguem suas práticas.

\section{Considerações finais}

Apoiamo-nos no que disse Lacan em um programa de televisão, posteriormente transformado por ele em texto: "Quanto mais somos santos, mais rimos, esse é meu princípio, ou até mesmo a saída do discurso capitalista - o que não constituirá um progresso, se for apenas para alguns" (Lacan, 2001/2003b, p. 519). A pertinência da escuta do psicólogo precavido pela psicanálise é factível e importantíssima para muitos sujeitos que estão na UPA, acompanhantes ou em tratamento, e não pretende se reservar a uns poucos em detrimento de muitos. Ora, se dissemos que nossa práxis é para todos, é porque apostamos no público, e não no privado entendido como restrito a umas poucas pessoas.

Por meio de alguns casos, pude perceber que, na UPA, o fato de possuir um psicólogo, pura e simplesmente, não seria interessante, um psicólogo como costumeiramente o conhecemos, em sua sala, aguardando ser acionado pelo restante da equipe. O trabalho se articulou com maior facilidade justamente por conta da equipe: enfermeiros, técnicos, auxiliares, recepcionistas e médicos. O motivo dos trabalhadores me conhecerem, saberem do meu papel no estabelecimento, possibilitou o acesso a alguns sujeitos que, de outro modo, não teriam vindo até mim. A constituição de um campo transferencial com os

\footnotetext{
${ }^{6}$ Dominique Miller (1989) define três movimentos da transferência numa análise. A transferência anônima é esse momento em que o sujeito não diferenciaria o analista de uma relação com qualquer outra pessoa, um médico, um padre ou um amigo, por exemplo. A transferência de significação é o tempo de abertura do inconsciente, quando o sintoma é questionado e o discurso se torna um saber suposto no discurso analítico. A transferência analítica é o momento em que o sujeito está no lugar do trabalho, em implicação subjetiva, produzindo outros sentidos ao sofrimento e retificando-se quanto à sua posição inicial, de outrora, de estar refém e objeto do seu sintoma em estado bruto.
} 
trabalhadores calhou aos intentos do psicólogo, tendo em vista que pretendíamos produzir intercessões no estabelecimento institucional para que a Psicanálise pudesse se realizar nesse contexto.

Um dos objetivos do psicólogo na UPA foi testemunhar a manifestação dos fenômenos do inconsciente à equipe. E como? No caso a caso, pontualmente, mediante o surgimento das situações. Os profissionais da Unidade indignavam-se, ficavam inconformados pelo motivo de existirem pessoas que não tinham "nada", mas pediam um soro e, consequentemente, conseguiam-no por indicação do médico, isto é, prescrição médica. Diante dos seus inconformismos, apresentava-lhes os exemplos de sujeitos que havia escutado, apontando-lhes elementos de suas demandas que nos sinalizava a importância de termos uma atenção diferenciada a eles.

Valeria indagarmos: de que adiantaria um psicólogo numa UPA que não o quisesse? A razão de não haver uma UPA funcionando em rede, no município onde a práxis ocorreu, na nossa leitura, inviabilizou a plena realização do dispositivo Clínica da Urgência. O que fizemos não contou com o apoio da sua coordenação. Nosso acesso ao estabelecimento foi devido à Secretaria Municipal de Saúde, após as recusas da representação do Consórcio Intermunicipal gerindo a Unidade. As ações ficaram reduzidas à permanência no prédio. Minhas idas às reuniões com os psicólogos da Atenção Básica foram enquanto representante da Secretaria de Saúde, sem a participação da coordenação. Por que tocamos nesse assunto? Porque a experiência do trabalho nos mostrou que o psicólogo, bem como a Clínica da Urgência, só terão sentido de existir se forem alicerçados sobre os pilares do SUS e da Saúde Coletiva: a integralidade (a compreensão da saúde e do adoecimento em seu todo, nos diversos setores da vida), a equidade (o cuidado e o acolhimento aos sujeitos que mais necessitam, têm mais carência, urgência quanto às suas necessidades e demandas), a universalidade (o acesso à saúde em território nacional garantido pelo Estado a todos, sem distinções de classe, raça, país de origem, sexualidade ou quaisquer outras características), a horizontalização nas relações de trabalho e o incentivo ao trabalho intersetorial de políticas públicas sociais.

Indicamos a pertinência da inclusão de um psicólogo precavido pela Psicanálise na estrutura de organograma e fluxograma de uma UPA, inserido nas relações hierárquicas e de organização das funções de trabalho no funcionamento do estabelecimento de Saúde. Esse psicólogo poderia ser um agente institucional, posicionando-se para escutar os sujeitos em sofrimento e as muitas demandas a eles associadas. Haveria a possibilidade de diversificar as ofertas transferenciais de atendimento na proposição de: oficinas, grupos psicoterapêuticos, trabalhos de inclinação psicanalítica destinados aos acompanhantes e/ou aos sujeitos em tratamento, individual ou em grupo.

As atividades trabalhistas, legitimadas pela legislação do SUS como elas já o são (Brasil, 1990), com a participação do psicólogo teriam a chance de ser realizadas de maneira intersetorial, partilhada em sua construção eentre os membros da equipe-UPA e entre as demais instituições da rede, seja ela de Saúde, de Assistência Social, de Educação e outros pontos das políticas de atendimento ao público que forem necessários para pensar e conduzir os casos. Esclarecemos que as funções realizadas de múltiplas ofertas de práticas de saúde e de articulação intersetorial de rede, do ponto de vista da proposição ética da Saúde Coletiva, são congruentes com a proposta de Atenção em uma unidade hospitalar. Colocam-se como uma saída possível do cenário alarmante de sucateamento e precarização do trabalho na Saúde Pública em geral.

A partir disso, concluímos que o tipo de psicólogo vislumbrado por nós não precisaria ser exclusivo ou limitar-se à atuação na UPA. Importar-nos-ia que fosse um articulador de rede na atenção à população, atento ao necessário trabalho cooperado no estabelecimento e entre os estabelecimentos de saúde. Nesse modo de compreensão da Clínica da Urgência, encontra-se um piso sólido aos horizontes da Psicanálise ampliada em sua intensão, essencial à escuta do sujeito do inconsciente em seus impasses e processos de adoecer.

\section{Referências}

Brasil. (1990). Lei no 8080, de 19 de setembro de 1990. Dispõe sobre as condições para promoção, proteção e recuperação da saúde, a organização e o financiamento dos serviços correspondentes e dá outras providências. http://www.planalto.gov.br/ccivil_03/leis/18080.htm 
Brasil. (2013). Portaria $n^{\circ} 342$, de 4 de março de 2013. Redefine as diretrizes para implantação do Componente Unidade de Pronto Atendimento (UPA 24h) em conformidade com a Política Nacional de Atenção às Urgências, e dispõe sobre incentivo financeiro de investimento para novas UPA 24h (UPA Nova) e UPA 24h ampliadas (UPA Ampliada) e respectivo incentivo financeiro de custeio mensal. http://bvsms.saude.gov.br/bvs/saudelegis/ gm/2013/prt0342_04_03_2013.html

Calazans, R., \& Bastos, A. (2008). Urgência subjetiva e clínica psicanalítica. Revista Latinoamericana de Psicopatologia Fundamental, 11(4), 640-652. http://www.scielo.br/pdf/rlpf/v11n4/v11n4a10.pdf

Calazans, R., \& Marçal, J. (2011). Os atos do sujeito e a certeza: algumas considerações sobre a clínica psicanalítica na urgência. Revista aSEPHallus, 6(12). http://www.isepol.com/asephallus/numero_12/artigo_04.html

Costa-Rosa, A. (1987). Saúde mental comunitária: Análise dialética das práticas alternativas [Dissertação de mestrado]. Universidade de São Paulo.

Costa-Rosa, A. (2013a). Atenção psicossocial além da Reforma Psiquiátrica: contribuições a uma Clínica Crítica dos processos de subjetivação na Saúde Coletiva. Unesp.

Costa-Rosa, A. (2013b). Uma ética para a Atenção Psicossocial: O cuidado em análise. In A. Costa-Rosa, Atenção psicossocial além da Reforma Psiquiátrica: contribuições a uma Clínica Crítica dos processos de subjetivação na Saúde Coletiva (pp. 271-322). esp.

Costa-Rosa, A. (2015). Por que a Atenção Psicossocial exige uma clínica fundada na Psicanálise do Campo FreudLacan? [Trabalho não publicado]. Universidade Estadual Paulista "Júlio de Mesquita Filho".

Elia, L. (2010). Clínica e pesquisa na instituição pública de tratamento de crianças e adolescentes autistas e psicóticos. Associação Psicanalítica de Curitiba em Revista, (20), 87-108. http://pesquisa.bvs.br/brasil/resource/pt/psi-48435

Figueiredo, A. C. (1997). Vastas confusões e atendimentos imperfeitos: A clínica psicanalítica no ambulatório público. Relume-Dumará.

Freud, S. (1996). II Casos Clínicos [(4) Katharina - (Freud)]. In Edição standard brasileira das obras psicológicas completas de Sigmund Freud (J. Salomão, Trad., Vol. 2, pp. 151-160). Imago. (Trabalho original publicado em 1893)

Freud, S. (1996). Análise de uma fobia em um menino de cinco anos. In Edição standard brasileira das obras psicológicas completas de Sigmund Freud (J. Salomão, Trad., Vol. 10, pp. 13-136). Imago. (Trabalho original publicado em 1909)

Freud, S. (1996). Sobre o narcisismo: uma introdução. In Edição standard brasileira das obras psicológicas completas de Sigmund Freud (J. Salomão, Trad., Vol. 14, pp. 77-110). Imago. (Trabalho original publicado em 1914)

Freud, S. (1996). Linhas de progresso na terapia psicanalítica. In Edição standard brasileira das obras psicológicas completas de Sigmund Freud (J. Salomão, Trad., Vol. 17, pp. 171-184). Imago. (Trabalho original publicado em 1919 [1918])

Freud, S. (1996). Além do princípio de prazer. In Edição standard brasileira das obras psicológicas completas de Sigmund Freud (J. Salomão, Trad., Vol. 18, pp. 13-78). Imago. (Trabalho original publicado em 1920)

Lacan, J. (1983). O seminário, livro 1: Os escritos técnicos de Freud, 1975 (B. Milan, Trad., 2a ed.). Zahar.

Lacan, J. (1998a). A direção do tratamento e os princípios de seu poder. In Escritos (V. Ribeiro, Trad., pp. 591-652). Zahar. (Trabalho original publicado em 1966)

Lacan, J. (1998b). Variantes do tratamento-padrão. In Escritos (V. Ribeiro, Trad., pp. 325-364). Zahar. (Trabalho original publicado em 1966)

Lacan, J. (2001). O lugar da psicanálise na medicina (M. A. Vieira, Trad.). Opção Lacaniana, (32), 8-14. (Trabalho original publicado em 1966)

Lacan, J. (2003a). Proposição de 9 de outubro de 1967 sobre o psicanalista da Escola. In Outros escritos (V. Ribeiro, Trad., pp. 248-264). Zahar. (Trabalho original publicado em 2001)

Lacan, J. (2003b). Televisão. In Outros escritos (V. Ribeiro, Trad., pp. 508-543). Zahar. (Trabalho original publicado em 2001)

Lourau, R. (2014). A análise institucional (3a ed.). Vozes. (Trabalho original publicado em 1970)

Lustosa, P. R. (2003). A pesquisa em psicanálise: Entre a técnica, a extensão e a intensão. Estados Gerais da Psicanálise: II Encontro Mundial. http://egp.dreamhosters.com/encontros/mundial_rj/download/ 3e_Lustosa_35010903_port.pdf

Luz, M. T. (1979). As instituições médicas no Brasil. Graal. 
Miller, D. (1989). As três transferências. In D. Miller, Clínica lacaniana: Casos clínicos do campo freudiano (L. Forbes, Trad., pp. 44-50). Zahar.

Moretto, M. L. T. (2001). O que pode um analista no hospital? Casa do Psicólogo.

Moura, M. D. (2000). Psicanálise e urgência subjetiva. In M. D. Moura (Org.), Psicanálise e hospital (2a ed., pp. 3-16). Revinter.

Nazar, T. P. (1985). Sujeito suposto saber: Dom de mestria. Revirão: Revista da Prática Freudiana, (1), 105-109.

Quinet, A. (2005). As 4+1 condições da análise. Zahar.

Rinaldi, D., \& Alberti, S. (2009). Psicanálise, saúde mental e universidade. Estudos e Pesquisas em Psicologia, 9(2), 533-545. http://www.revispsi.uerj.br/v9n2/artigos/pdf/v9n2a18.pdf

Soares, E. (2009). A Psicanálise em extensão e sua intensão. Revista Eletrônica do Núcleo Sephora, 4(8). http:// www.isepol.com/asephallus/numero_08/artigo_07_port.html

\section{Maico Fernando Costa}

Doutorando em Psicologia e Sociedade pela Universidade Estadual Paulista Júlio de Mesquita Filho (Unesp), Assis - SP. Brasil.

E-mail: maicofernandodd@gmail.com

(1) https://orcid.org/0000-0001-6540-774X

Abílio da Costa-Rosa

Psicanalista e Analista Institucional. Professor livre-docente em Psicologia Clínica pela Universidade Estadual Paulista Júlio de Mesquita Filho, Assis - SP. Brasil.

(1) https://orcid.org/0000-0002-7648-0114

In memoriam

Dedico a publicação deste artigo ao psicanalista, meu antigo orientador, Abílio da Costa-Rosa, a quem tive e sempre terei como referência de postura ética na práxis da vida. $O$ seu legado continua, por meio daqueles que indireta ou diretamente conseguiram ter a oportunidade de viver a sua transmissão. Agradecimentos à Fundação de Amparo à Pesquisa do Estado de São Paulo (Fapesp), presente desde a graduação, pelo financiamento da pesquisa que originou este artigo.

Endereço para envio de correspondência:

Universidade Estadual Paulista Júlio de Mesquita Filho - Campus Assis. Av. Dom Antônio, 2100. Parque Universitário. CEP: 19 806-900. São Paulo - SP. Brasil.

Recebido 29/01/2019

Aceito 11/05/2020

Received $01 / 29 / 2019$

Approved 05/11/2020

Recibido 29/01/2019

Aceptado 11/05/2020 
Costa, M. F., \& Costa-Rosa, A. (2021). Considerações sobre a Ampliação da Intensão da Psicanálise.

Como citar: Costa, M. F. \& Costa-Rosa, A. (2021). Considerações sobre a ampliação da Intensão da Psicanálise numa Unidade de Pronto Atendimento. Psicologia: Ciência e Profissão, 41, 1-15. https://doi.org/10.1590/ 1982-3703003219208

How to cite: Costa, M. F. \& Costa-Rosa, A. (2021). Considerations about the enlargement of the Intention of Psychoanalysis in the EUC. Psicologia: Ciência e Profissão, 41, 1-15. https://doi.org/10.1590/1982-3703003219208

Cómo citar: Costa, M. F. \& Costa-Rosa, A. (2021). Consideraciones sobre una ampliación de Intenso da Psicanálise una UPA. Psicologia: Ciência e Profissão, 41, 1-15. https://doi.org/10.1590/1982-3703003219208 